\title{
Activation of SIRT1 promotes cartilage differentiation and reduces apoptosis of nucleus pulposus mesenchymal stem cells via the MCP1/CCR2 axis in subjects with intervertebral disc degeneration
}

\author{
XUANCHENG OU ${ }^{1,2}$, JINWEI YING $^{3}$, XUEDONG BAI $^{2}$, CHAOFENG WANG $^{2}$ and DIKE RUAN ${ }^{1,2}$ \\ ${ }^{1}$ The Second School of Clinical Medicine, Southern Medical University, Guangzhou, Guangdong 510515; \\ ${ }^{2}$ Department of Orthopedic Surgery, The Sixth Medical Centre of PLA General Hospital, Beijing 100048; \\ ${ }^{3}$ Department of Orthopedic Surgery, The First Affiliated Hospital of Wenzhou Medical University, \\ Wenzhou, Zhejiang 325000, P.R. China
}

Received January 17, 2020; Accepted May 7, 2020

DOI: $10.3892 /$ ijmm.2020.4668

\begin{abstract}
Intervertebral disc degeneration (IDD) is a condition involving disruption of the bone tissue distribution. Nucleus pulposus mesenchymal stem cells (NPMSCs) and Sirtuin 1 (SIRT1) play important roles in bone diseases, therefore the aim of the present study was to evaluate the roles of SIRT1 and NPMSCs in IDD. First, NPMSCs were harvested from patients with IDD. Then, the NPMSCs were treated with a SIRT activator, and monocyte chemoattractant protein 1 (MCP1) and chemokine receptor 2 (CCR2) inhibitors. Indices related to NPMSC growth, proliferation, differentiation and apoptosis were measured. Subsequently, IDD rat models were established and were transfected with NPMSCs overexpressing SIRT1. NPMSC apoptosis and cartilage differentiation were detected in the rat IDD model. SIRT1 expression was found to be decreased, and the expression of MCP1 and CCR2 increased in NPMSCs of patients with IDD. The upregulation of SIRT1 and the downregulation of the MCP1/CCR2 axis promoted cartilage differentiation and reduced the number of apoptotic NPMSCs. Furthermore, MCP1 reversed the progression of the cartilage differentiation of NPMSCs and the inhibition of NPMSC apoptosis induced by SIRT1 overexpression. Moreover, the transplantation of rat NPMSCs overexpressing SIRT1 relieved IDD in rats. Therefore, SIRT1 overexpression improved cartilage differentiation and reduced the apoptosis
\end{abstract}

Correspondence to: Dr Dike Ruan, The Second School of Clinical Medicine, Southern Medical University, 1023 South Shatai Road, Guangzhou, Guangdong 510515, P.R. China

E-mail: drruandk0925@163.com

Key words: intervertebral disc degeneration, nucleus pulposus mesenchymal stem cells, Sirtuin 1, monocyte chemoattractant protein 1 , chemokine receptor 2 , apoptosis of NPMSCs by inactivating the MCP1/CCR2 axis, thus attenuating IDD in rats.

\section{Introduction}

Intervertebral disc degeneration (IDD) is closely related to lower back pain induced by inflammatory responses, nerve ingrowth in degenerated intervertebral discs and degradation of the extracellular matrix (ECM), which cause subsequent changes in spinal biomechanics. IDD can have a large impact on the livelihood of patients and their economic development (1). IDD disrupts the distribution and density of the aged bone tissues in vertebrae (2). Nucleus pulposus (NP) mesenchymal stem cells (MSCs) can promote the regeneration of intervertebral discs due to their endogenous repair function (3). Furthermore, since a loss of NP cells and the ECM are the primary causes of IDD, and MSC differentiation is conducive to intervertebral disc regeneration, the ability of NPMSCs to form cartilage can help to protect patients with IDD (4). MSCs reduce stress-mediated NP cell apoptosis, thus relieving the severity of IDD (5). Currently, IDD, which is associated with the accumulation of injuries and aging, is a health threat to millions of individuals worldwide (6). In this context, biomarkers for early stage diagnosis and novel therapeutic strategies for IDD are urgently needed. As stem cell transplantation is an effective therapy for IDD (7), the present study focused on the underlying mechanisms of NPMSCs, as well as their roles in cartilage differentiation and apoptosis, to develop novel intervention strategies.

Sirtuins (SIRTs) are actively involved in preventing cell senescence and prolonging the lifespan of an organism by modulating various cell biological processes, including apoptosis, transcription and angiogenic metabolism (8). Suppression of SIRT activity is related to abnormalities in physiological development, such as short stature, bone fragility and craniofacial dimorphisms, whereas SIRT overexpression protects bones from damage caused by aging or immobilization (9). As a member of the SIRT family, SIRT1, 
whose dysfunction may trigger skeletal diseases, directly acts on bone cells and cartilage, and it plays an important role in maintaining bone homeostasis and growth (10). Additionally, activated SIRT1 in MSCs restores the osteoblastic bone formation (11). Moreover, recently it has been reported that both monocyte chemoattractant protein 1 (MCP1) and chemokine receptor 2 (CCR2) are overexpressed in the spinal cord of patients with cancer-induced bone pain (CIBP), indicating a severe and long-lasting CIBP (12). MCP1 is expressed at high levels in obese children, who are vulnerable to fractures and osteoporosis (13) Additionally, MCP1 is secreted at higher levels in ankylosing spondylitis MSCs than it is in normal MSCs (14). High levels of CCR2 is present in the peripheral blood of patients with osteoarthritis (15). Moreover, increased CCR2 expression has been observed in mice with bone fractures, and it further exaggerates bone fracture and its complications (16). In a recent study, the crosstalk of MCP1 and CCR2 is increased in response to diverse stimuli, potentially resulting in severe osteoclastogenesis (13). Based on accumulating evidence, SIRT1 knockout increases MCP1 expression in individuals with various diseases, such as atherosclerosis and disc degeneration, thus further worsening the severity of the symptoms $(17,18)$. Therefore, a reasonable hypothesis is that the interaction between SIRT1 and the MCP1/CCR2 axis represents a useful target in IDD treatment. Thus, in the present study a series of experiments were conducted to verify the hypothesis.

\section{Materials and methods}

Separation and culture of NPMSCs. Between May 2016 and July 2019, 20 patients with lumbar disc herniation (LDH; 12 men and 8 women, with the age ranging from 60-75 years) and 10 patients with lumbar vertebral fracture (LVF; 8 men and 2 women, with the age ranging from 20-25 years) who received an operation at The Sixth Medical Centre of PLA General Hospital were enrolled in this study for the collection of NP samples. All 20 patients with LDH were diagnosed with IDD through magnetic resonance imaging prior to the operation and a pathological examination post-operation. Additionally, the 10 patients with LVF were treated with urgent surgical decompression, discectomy and fusion with internal fixation within $24 \mathrm{~h}$ after trauma. NP samples were collected from the patients with LVF during the operation and served as controls for the samples from patients with $\mathrm{LDH}$.

The annulus fibrosus of the samples was transected using a scalpel to expose the NP, and then the NP tissues were removed. NP tissue samples were minced and washed in PBS, and then centrifuged at $500 \mathrm{x}$ g for $5 \mathrm{~min}$ at room temperature, after which the supernatant was discarded. Next, the NP cells were detached by incubating the samples with $0.25 \%$ trypsin at $37^{\circ} \mathrm{C}$ for $20 \mathrm{~min}$ and centrifuged at $500 \mathrm{x} \mathrm{g}$ at room temperature for $5 \mathrm{~min}$ to discard the supernatant. Next, the NP cells were treated with $0.25 \%$ collagen II at $37^{\circ} \mathrm{C}$ for $4 \mathrm{~h}$, followed by centrifugation at $500 \mathrm{x} \mathrm{g}$ for $5 \mathrm{~min}$ at room temperature, following which the supernatant was discarded. The cell suspension was seeded in a cell culture flask with Dulbecco's modified Eagle's medium (DMEM)/F12 (Thermo Fisher Scientific, Inc.) containing $15 \%$ fetal bovine serum (FBS; Beijing Solarbio
Science \& Technology Co., Ltd.). The flask was placed in a $37^{\circ} \mathrm{C}$ incubator with $5 \% \mathrm{CO}_{2}$. The medium was replaced every 3 or 4 days. Cell growth was observed under an inverted microscope (Olympus Corporation). At $\sim$ day 15, the fast-growing cells aggregated into a mass, requiring ongoing subculture. Then, adherent cells were detached with $0.25 \%$ trypsin and subcultured at a ratio of 1:2. Passage 2 NPMSCs exhibiting good growth under a microscope were collected for further experiments.

Identification of NPMSCs. After detachment in $0.25 \%$ trypsin, the passage 2 NPMSCs were incubated with fluorescein isothiocyanate (FITC)-conjugated primary antibodies (all from Abcam) against CD34 (1:50; cat. no. ab78165), CD45 (1:50; cat. no. ab27287), CD73 (1:50; cat. no. ab54217) and CD90 (1:50; cat. no. ab124527) at $4^{\circ} \mathrm{C}$ for $45 \mathrm{~min}$ in the dark. An appropriate negative control (NC) was established for each tube. After washing with PBS three times, cells were centrifuged at $400 \mathrm{x} \mathrm{g}$ for $5 \mathrm{~min}$ at $4^{\circ} \mathrm{C}$, resuspended in $50 \mu \mathrm{lPBS}$, and verified using a flow cytometer (BD FACSCanto ${ }^{\mathrm{TM}}$ II) and BD FACSDiva $^{\mathrm{TM}} 6.0$ software (BD Biosciences).

The passage 2 NPMSCs were cultured in osteogenic cartilage differentiation medium (low-glucose DMEM supplemented with $0.01 \%$ dexamethasone, $10 \mathrm{mmol} / 1 \beta$-sodium glycerophosphate, $50 \mu \mathrm{g} / \mathrm{ml}$ vitamin, $1 \%$ penicillin-streptomycin, $1 \%$ glutamine and 10\% FBS), lipogenic differentiation medium (high-glucose DMEM supplemented with $0.1 \%$ dexamethasone, $0.1 \%$ isobutylmethylxanthine, $1 \%$ penicillin-streptomycin, $1 \%$ glutamine, $10 \mu \mathrm{mol} / 1$ insulin and $10 \%$ FBS) or chondroblast differentiation medium (DMEM/F12 supplemented with $0.01 \%$ dexamethasone, $10 \mathrm{ng} / \mathrm{ml}$ transforming growth factor- $\beta 1,50 \mathrm{mg} / \mathrm{l}$ vitamin, $6.25 \mu \mathrm{g} / \mathrm{ml}$ transferrin, $1 \%$ penicillin-streptomycin, $1 \%$ glutamine and $10 \%$ FBS), all purchased from Beijing Solarbio Science \& Technology Co., Ltd. The medium was replaced every 3 days. Blank controls with no inducer added to the medium were also prepared.

After a 3-week induction of adipogenic and osteoplastic differentiation, cells were fixed with $4 \%$ paraformaldehyde for $15 \mathrm{~min}$ at room temperature and stained with alizarin red for $20 \mathrm{~min}$ and oil red $\mathrm{O}$ for $10 \mathrm{~min}$. After a 3-week induction of chondrogenic differentiation, cell microspheres were collected, fixed with $4 \%$ paraformaldehyde for $15 \mathrm{~min}$ at room temperature, embedded in paraffin, cut into $4 \mu \mathrm{m}$ sections and stained with alcian blue for $30 \mathrm{~min}$ at room temperature. Next, these sections were observed under an optical microscope and photographed. Alcian blue, alizarin red and oil red $\mathrm{O}$ were all purchased from Beyotime Institute of Biotechnology.

\section{3-(4,5-Dimethylthiazol-2-yl)-2,5-diphenyltetrazolium bromide} (MTT) assay. Passage 2 NPMSCs were seeded into 96-well plates at a density of $1 \times 10^{3}$ cells/well and incubated in a $37^{\circ} \mathrm{C}$ incubator with a 5\% $\mathrm{CO}_{2}$ atmosphere. Then, $20 \mu 1 \mathrm{MTT}$ solution (5 mg/ml; Beijing Solarbio Science \& Technology Co., Ltd.) was added to 3 different wells on days 2, 4, 6, 8 and 10, and cells were incubated at $37^{\circ} \mathrm{C}$ for an additional $4 \mathrm{~h}$. Subsequently, the solution in each well was replaced with $150 \mu 1 \mathrm{DMSO}$ and incubated at $37^{\circ} \mathrm{C}$ for $30 \mathrm{~min}$. Then, the optical density value of each well was recorded at $492 \mathrm{~nm}$ using a microplate reader (ThermoMax; Molecular Devices, LLC). 
Experimental groups and treatments. Cells were assigned into the following groups: i) Blank group, NPMSCs from patients with LVF without any treatment; ii) LDH group, NPMSCs from patients with LDH without any treatment; iii) resveratrol (RES) group, $50 \mu \mathrm{mol} / 1$ RES ( SIRT1 agonist) was added to NPMSCs from patients with LDH; iv) MCP1 group, $50 \mathrm{ng} / \mathrm{ml}$ MCP1 was added to NPMSCs from patients with LDH; v) RS102895 group, $10 \mu \mathrm{mol} / 1 \mathrm{RS} 102895$ (CCR2 inhibitor) was added to NPMSCs from patients with LDH; and vi) RES + MCP1 group, $50 \mu \mathrm{mol} / 1 \mathrm{RES}$ and $50 \mathrm{ng} / \mathrm{ml} \mathrm{MCP1}$ were added to NPMSCs from patients with LDH. RES, MCP1 and RS102895 were all purchased from Beyotime Institute of Biotechnology.

Reverse transcription-quantitative polymerase chain reaction ( $R T-q P C R$ ). A TRIzol kit (Beijing Dingguo Changsheng Biotechnology Co., Ltd.) was utilized to extract total RNA from cells and tissue homogenates in each group. RNA concentration and purity were measured, and the extracted RNA was reverse transcribed into cDNAs using a ReverTra Ace ${ }^{\circledast}$ qPCR RT Master Mix kit (Toyobo Life Science). The conditions of reverse transcription were: Genomic DNA eraser at $42^{\circ} \mathrm{C}$ for $2 \mathrm{~min}, 37^{\circ} \mathrm{C}$ for $15 \mathrm{~min}$ and $85^{\circ} \mathrm{C}$ for $5 \mathrm{sec}$. PCR was conducted using SYBR Premix Ex Taq $^{\mathrm{TM}}$ II (Takara Bio, Inc.) with $\beta$-actin as an internal reference. PCR conditions were as follows: Pre-denaturation at $95^{\circ} \mathrm{C}$ for $5 \mathrm{~min}$; then 40 cycles of denaturation at $95^{\circ} \mathrm{C}$ for $10 \mathrm{sec}$ and annealing at $60^{\circ} \mathrm{C}$ for $20 \mathrm{sec}$; and final extension at $72^{\circ} \mathrm{C}$ for $10 \mathrm{sec}$. Relative gene expression was measured using the $2^{-\triangle \Delta C \mathrm{C}}$ method (PMID:11846609). The primer sequences are listed in Table I.

Western blot analysis. Total proteins were extracted from cells using a protein extraction kit (Beijing Solarbio Science \& Technology Co., Ltd.) and tissue homogenates in each group and the concentrations were measured by a bicinchoninic acid protein assay kit (Beyotime Institute of Biotechnology). Proteins (20 g) were loaded onto 6-15\% gels and resolved via SDS-PAGE, and then transferred Onto polyvinylidene fluoride membranes (Beyotime Institute of Biotechnology). Next, the membranes were blocked with 5\% skimmed milk powder for $1 \mathrm{~h}$ at room temperature and incubated with primary antibodies (all purchased from Abcam) against MCP1 (1:2,000; cat. no. ab25124), CCR2 (1:1,000; cat. no. ab203128), aggrecan (1:100; cat. no. ab3778), collagen II (1:1,000; cat. no. ab34712), Sry-related HMG box (Sox)-9 (1:1,000; cat.no. ab185966), Bcl-2 (1:1,000; cat. no. ab32124), Bax (1:1,000; cat. no. ab32503), cleaved caspase-3 (1:1,000; cat. no. ab2302), matrix metalloproteinase (MMP)-13 (1:3,000; cat. no. ab39012), tissue inhibitor of metalloproteinase 1 (TIMP-1; 1:1,000; cat. no. ab38978) and SIRT1 $\left(1: 2,000\right.$; cat. no. ab110304) at $4^{\circ} \mathrm{C}$ overnight. Afterwards, the membranes were incubated with a horseradish peroxidase-conjugated goat anti-rabbit immunoglobulin $\mathrm{G}$ antibody (1:2,000; cat. no. ab205718) at room temperature for $1 \mathrm{~h}$. Following incubation, the membranes were developed using enhanced chemiluminescence reagent (Beijing Solarbio Science \& Technology Co., Ltd.) and visualized using BioSpectrum gel imaging system (Bio-Rad Laboratories, Inc.). The protein bands were analyzed by Image-Pro Plus 6.0 (Media Cybernetics, Inc.). GAPDH (1:1,000; cat. no. ab8245)
Table I. Primer sequences used for RT-qPCR.

\begin{tabular}{ll}
\hline Gene & \multicolumn{1}{c}{ Primer sequence $\left(5^{\prime} \rightarrow 3^{\prime}\right)$} \\
\hline 4-Oct & F: GTATTCAGCCAAACGACCATCT \\
& R: GCTTCCTCCACCCACTTCT \\
Nanog & F: ACCCCGTTCACTGTGTAGC \\
& R: GACGGCAGCCAAGGTTATTAA \\
Collagen II & F: AAGAAGCACATCTGGTTTGA \\
& R: CAGTGGACAGTAGACGGAGGA \\
Aggrecan & F: CGAGAATCAAATGGAGCCG \\
& R: CACAACACCTTTCACCACGAC \\
Sox-9 & F: GACAACTTTACCAGTTTCGGTC \\
& R: GAGGGAAAACAGAGAACGAAAC \\
MCP-1 & F: TCTCTTCCTCCACCACTATGCA \\
& R: GGCTGAGACAGCACGTGGAT \\
CCR2 & F: GGAATCTTCTTCATTATCCTCCTGAC \\
& R: TGACTACACTTGTTATTACCCCAAAGG \\
SIRT1 & F: CCAGAACATAGACACGCTGGAAC \\
& R: CTCCTCGTACAGCTTCACAGTCA \\
$\beta$-actin & F: TGGCTGGCCGGGACCTGACTGA \\
& R: CGCGCCGTGGCCATCTCCTG
\end{tabular}

F, forward; R, reverse; Oct, Octamer; Sox, Sry related HMG box; $\mathrm{MCP}$, monocyte chemoattractant protein; CCR, chemokine (C-C motif) receptor; SIRT, sirtuin.

served as the internal reference, and the ratio of the gray value of the target protein to GAPDH was recorded as the relative protein expression.

Flow cytometry detection of Annexin V-FITC/propidium iodide (PI) staining. After detachment using 0.25\% trypsin followed by washing with PBS, NPMSCs were resuspended in $500 \mu \mathrm{l}$ binding buffer, and then were treated with $5 \mu \mathrm{l}$ Annexin V-FITC and $5 \mu \mathrm{l}$ PI. After a 15 -min reaction at room temperature, the mixture was detected and analyzed using a BD FACSCalibur ${ }^{\mathrm{TM}}$ flow cytometer and BD FACSDiva ${ }^{\mathrm{TM}} 6.0$ software (BD Biosciences). All the steps mentioned above were performed according to the instructions of the Annexin V-FITC/PI double-staining cell apoptosis detection kit (Nanjing KeyGen Biotech Co., Ltd.).

Rat model experimental groups and treatments. A total of 40 healthy 8 -week old Sprague-Dawley rats (weight, 220-250 g), purchased from Jinan University, Guangzhou, Guangdong, China [SYXK (Guangdong) 2017-0174], were raised under standard conditions at a temperature of $25 \pm 2{ }^{\circ} \mathrm{C}$, $45 \%$ relative humidity, controlled $12 \mathrm{~h}$ light/dark cycles, and free access to drinking water and food. One week later, they were subjected to experiments.

The rats were numbered by body weight and randomly assigned into the control group, the IDD group, the lentivirus (LV) NC group and the LV-SIRT1 group, with 10 rats per group. The normal rats in the control group received no treatment. Rats in the IDD group, the LVNC group and the LV-SIRT1 were subjected to a coccyx puncture to establish rat IDD models. Briefly, $60 \mathrm{mg} / \mathrm{kg}$ pentobarbital sodium 
was intraperitoneally injected into rats for anesthesia, and then the 5 and 6th (Co5-6) and 6 and 7th (Co6-7) coccygeal vertebrae of the rat intervertebral discs were located using a portable X-ray machine (Shanghai Xianwei Photoelectric Technology Co., Ltd.). Afterwards, $22 \mathrm{G}$ needles were used to pierce the Co5-6 and Co6-7, with the tips inserted perpendicular to rat tails until they had completely punctured through the other side $\left(5-\mathrm{mm}\right.$ depth, $360^{\circ}$ rotation for $5 \mathrm{sec}$ ) (19). Subsequently, 200,000 U/kg penicillin sodium salt (Shandong Lukang Record Pharmaceutical Co., Ltd.) was injected into each rat daily. When the models were successfully established, a rat NPMSC suspension $\left(2 \times 10^{6}\right.$ cells $\left./ \mathrm{ml}\right)$ that had been transfected with $1 \times 10^{8} \mathrm{TU} / \mathrm{ml}(\mathrm{MOI}=10) \mathrm{LV}$ NC or LV-SIRT1 was injected into rats in the LVNC group or the LV-SIRT1 group, respectively. The follow-up experiments were conducted 4 weeks after transfection. Both the construction and packaging of LV NC and LV-SIRT1 (lentivirus vector of SIRT1) were conducted by Shanghai GeneChem Co., Ltd.

Tissue sample collection. Four weeks after the aforementioned operation, all rats were euthanatized with an intraperitoneal injection of pentobarbital sodium (800 mg/kg) (20). Afterwards, intervertebral disc tissues were immediately removed. Tissues from 6 rats in each group were fixed with $4 \%$ paraformaldehyde overnight, embedded in paraffin and sectioned $(4 \mu \mathrm{m})$ for staining, and the tissues from the other 4 rats were used to prepare tissue homogenates.

Hematoxylinandeosin $(H \& E)$ staining. The paraffin-embedded sections were routinely dewaxed, dehydrated, stained with hematoxylin (Beijing Solarbio Science \& Technology Co., Ltd.) for $3 \mathrm{~min}$ at room temperature, washed, and differentiated in $1 \%$ acid alcohol for $15 \mathrm{sec}$. Next, these sections were stained with eosin (Beijing Solarbio Science \& Technology Co., Ltd.) for $2 \mathrm{~min}$ at room temperature and observed under an optical microscope (Olympus Corporation).

TdT-mediated dUTP nick-end labeling (TUNEL) staining. The paraffin-embedded sections were routinely dewaxed and dehydrated before apoptosis detection using a TUNEL kit (Shanghai Yeasen Biotechnology Co., Ltd.), according to the manufacturer's instructions, followed by incubation with $\mathrm{TdT}$ buffer at $37^{\circ} \mathrm{C}$ in the dark for $60 \mathrm{~min}$. Next, the cell nuclei were stained with $10 \mu \mathrm{g} / \mathrm{ml}$ DAPI (Beyotime Institute of Biotechnology) and incubated for $5 \mathrm{~min}$ at room temperature in the dark. Subsequently, the sections were sealed with anti-fluorescence quenching sealing agent (cat. no. 0100-01; SouthernBiotech) and 10 fields were randomly selected to observe TUNEL-positive cells under a fluorescence microscope.

Statistical analysis. SPSS v21.0 (IBM Corp.) was employed for data analysis. Kolmogorov-Smirnov tests were performed to determine the normal distribution of the data. The data are presented as the mean \pm standard deviation. For data comparing two groups, two-tailed t tests were used, whereas one-way ANOVA and two-way ANOVA were used to compare data between multiple groups followed by Tukey's post hoc test. $\mathrm{P}<0.05$ was considered to indicate a statistically significant difference.

\section{Results}

NPMSC identification and the differential expression of SIRT1 and genes related to the MCPI/CCR2 axis between NPMSCs from patients with LVF and $L D H$. Elongated spindle-shaped passage 2 NPMSCs from patients with LVF and LDH were observed under the optical microscope (Fig. 1A). According to the flow cytometry results, NPMSCs of the blank group and the LDH group expressed CD73 and CD90, but not CD34 and CD45 (Fig. 1B). Alizarin red, oil red $\mathrm{O}$ and alcian blue staining revealed the potential of NPMSCs in the blank group and the LDH group to undergo adipogenic, osteoplastic and chondrogenic differentiation (Fig. 1C-E). The MTT assay showed that the proliferation of NPMSCs was slower in the LDH group than in the blank group $(\mathrm{P}<0.01$; Fig. 1F). RT-qPCR revealed that the expression of Oct4 and Nanog mRNA in NPMSCs was lower in the LDH group compared with in the blank group (both $\mathrm{P}<0.01$; Fig. 1G). Compared with the blank group, the LDH group exhibited decreased expression of SIRT1 mRNA and protein, but increased expression of MCP1 and CCR2 mRNA and protein (Fig. 1H and I).

Overexpression of SIRT1 and downregulation of the $M C P 1 / C C R 2$ axis promote NPMSC cartilage differentiation but inhibit NPMSC apoptosis. Compared with the LDH group, the RES group displayed increased expression of SIRT1 mRNA and protein, the MCP1 group exhibited increased expression of MCP1 and CCR 2 mRNA and protein, whereas in the RS102895 group CCR2 mRNA and protein expression decreased (all $\mathrm{P}<0.05$; Fig. 2A-D). Compared with the LDH group, RES and RS102895 groups exhibited increased expression levels of aggrecan, collagen II and Sox-9 mRNA and protein, but the MCP1 group displayed decreased expression levels of aggrecan, collagen II and Sox-9 mRNA and protein (all $\mathrm{P}<0.01$; Fig. $2 \mathrm{E}$ and $\mathrm{F}$ ). According to the flow cytometry results, compared with the LDH group, apoptosis was decreased in the RES and RS102895 groups, and increased in the MCP1 group (all $\mathrm{P}<0.05$; Fig. 2G). Compared with the LDH group, the expression levels of Bax, cleaved caspase-3 and MMP13 protein in the RES group decreased, whereas Bcl-2 and TIMP-1 expression increased. The expression levels of Bax, Bcl-2, cleaved caspase-3 and TIMP-1 protein in the RS102895 groups increased compared with the LDH group, and MMP13 protein expression decreased. The MCP1 group presented the opposite results (all $\mathrm{P}<0.05$; Fig. $2 \mathrm{H}$ ).

Overexpression of SIRT1 downregulates the MCP1/CCR 2 axis. Lower expression levels of MCP1 and CCR2 mRNA and protein were observed in the RES group compared with in the LDH group. Higher expression levels of MCP1 and CCR 2 mRNA and protein were observed in the RES + MCP1 compared with in the RES group, but expression was lower compared with in the MCP1 group (all $\mathrm{P}<0.01$; Fig. $3 \mathrm{~A}$ and $\mathrm{B}$ ).

$M C P 1$ reverses the progression of NPMSC cartilage differentiation and the inhibition of NPMSC apoptosis induced by SIRT1 overexpression. Compared with the RES group, the RES + MCP1 group showed decreased mRNA and protein expression of aggrecan, collagen II and Sox-9, increased cell 
A

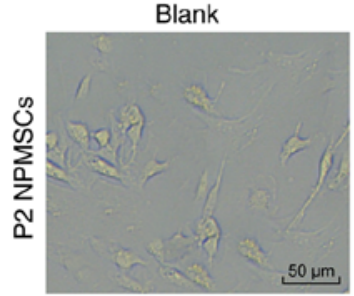

$\mathrm{LDH}$

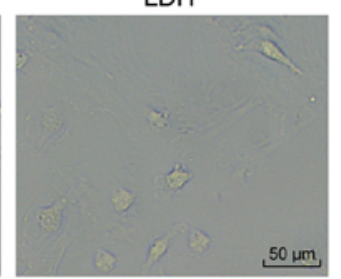

B
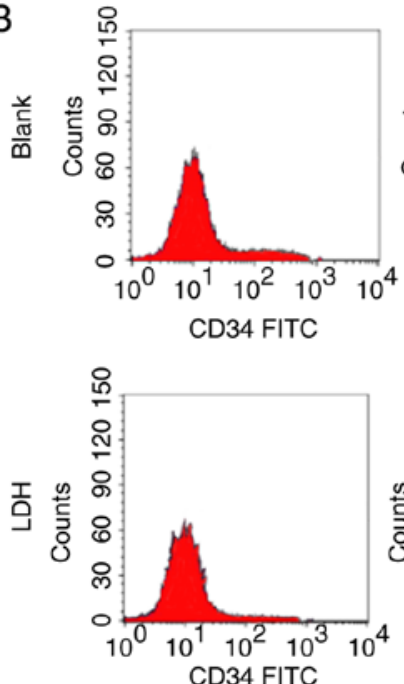

CD34 FITC

C
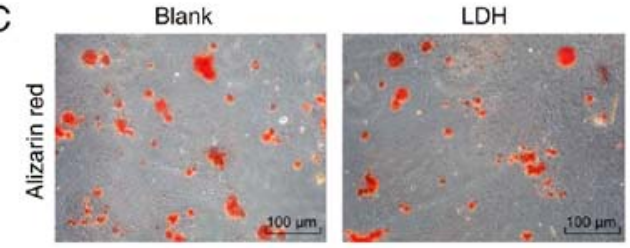

$\mathrm{E}$
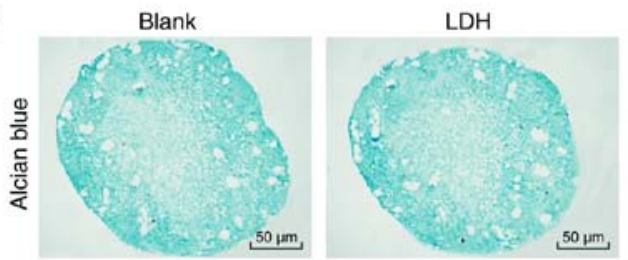

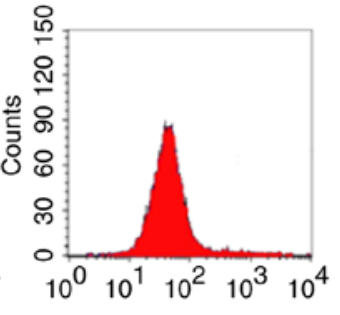

CD73 FITC

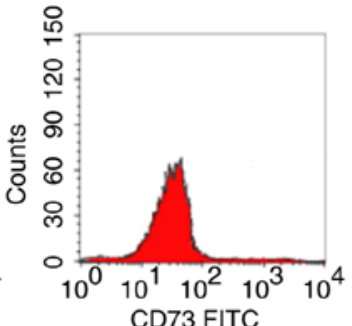

CD73 FITC
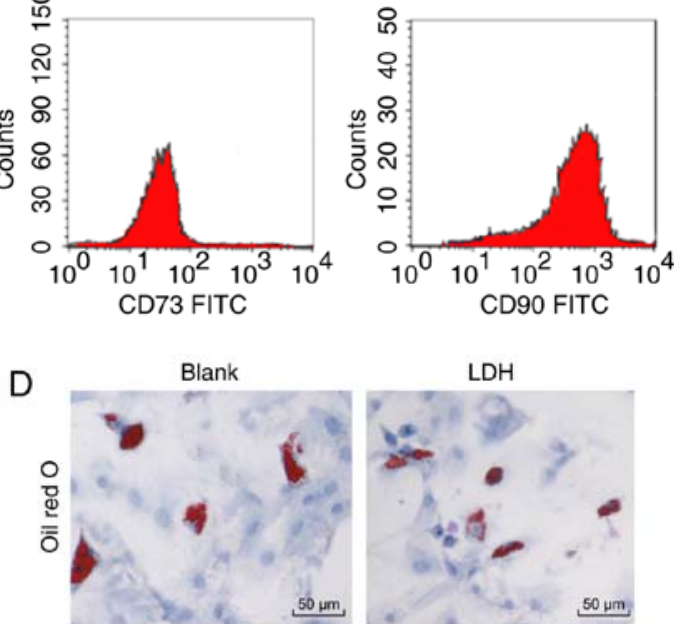

$\mathrm{LDH}$

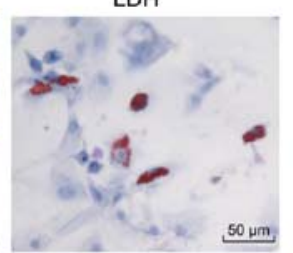

G
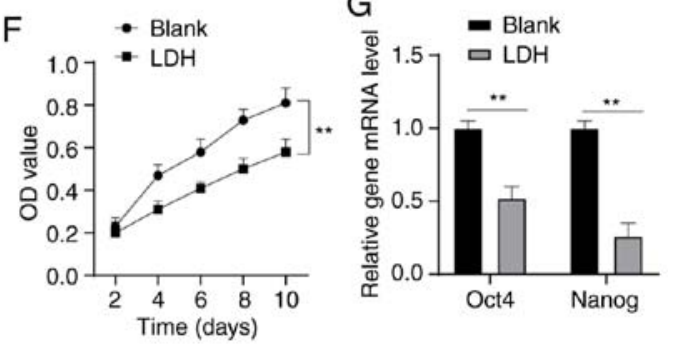

$\mathrm{H}$

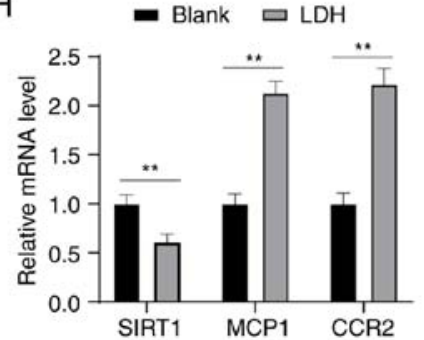

।
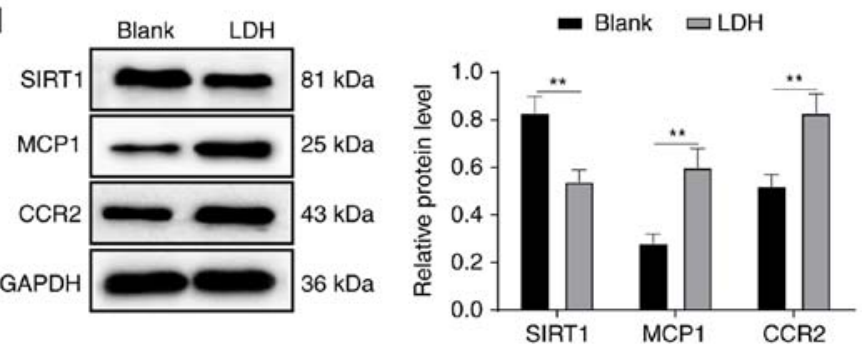

Figure 1. Roles of NPMSCs in IDD, as well as decreased SIRT1 expression and increased expression of genes related to the MCP1/CCR2 axis in LDH were verified. (A) Elongated spindle-shaped passage 2 NPMSCs from patients with LVF and LDH were observed under an optical microscope. (B) Flow cytometry revealed the expression of CD73 and CD90, but not CD34 and CD45, in NPMSCs from the blank group and the LDH group. (C) Alizarin red, (D) oil red O and (E) alcian blue staining revealed the potential of NPMSCs in the blank group and the LDH group to undergo adipogenic, osteoplastic and chondrogenic differentiation. (F) According to the results of the MTT assay, NPMSCs in the LDH group proliferated faster than NPMSCs in the blank group. (G) RT-qPCR revealed lower expression of Oct4 and Nanog mRNA in NPMSCs from the LDH group compared with in the blank group. (H and I) Compared with the blank group, the LDH group displayed lower mRNA and protein expression of SIRT1 and higher mRNA and protein expression of MCP1 and CCR2, based on the results of RT-qPCR and western blot analyses. Two-way ANOVA was used to analyze data in panels F-I. Tukey's multiple comparisons test was applied as the post hoc test. $n=3$. ${ }^{* *} \mathrm{P}<0.01$. NPMSC, nucleus pulposus mesenchymal stem cell; SIRT, Sirtuin; MCP, monocyte chemoattractant protein; CCR, chemokine receptor; LVF, lumbar vertebral fracture; LDH, lumbar disc herniation; MTT, 3-(4,5-dimethylthiazol-2-yl)-2,5-diphenyltetrazolium bromide; RT-qPCR, reverse transcription-quantitative polymerase chain reaction. 

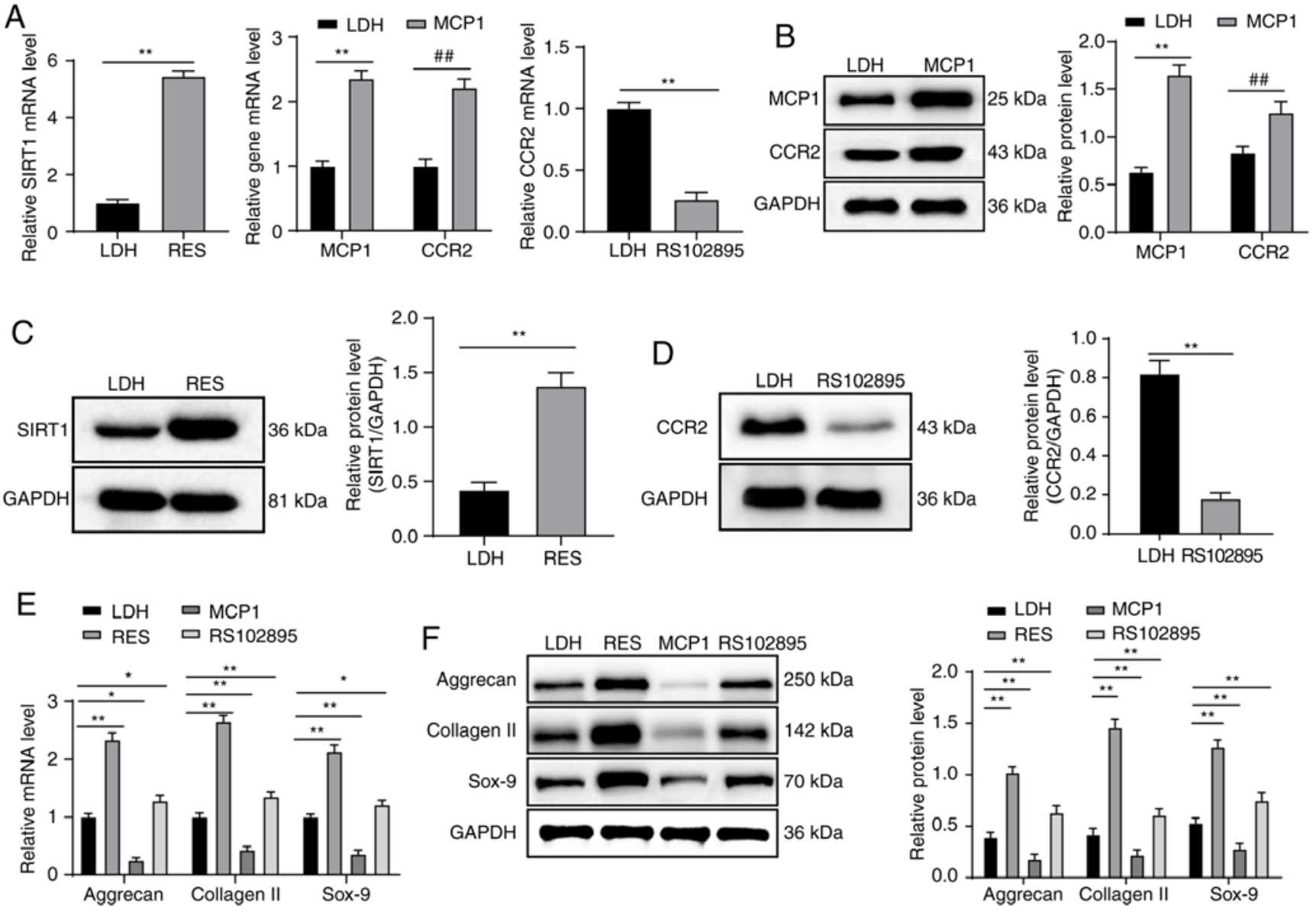

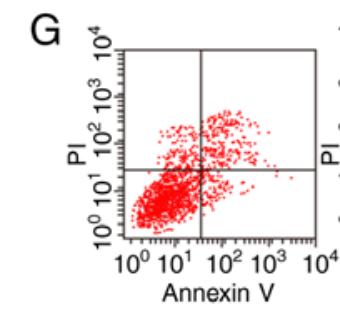

$\mathrm{LDH}$

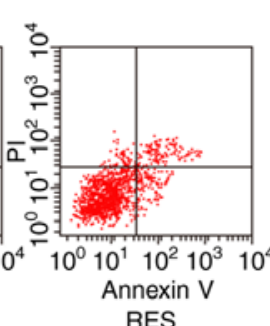

RES
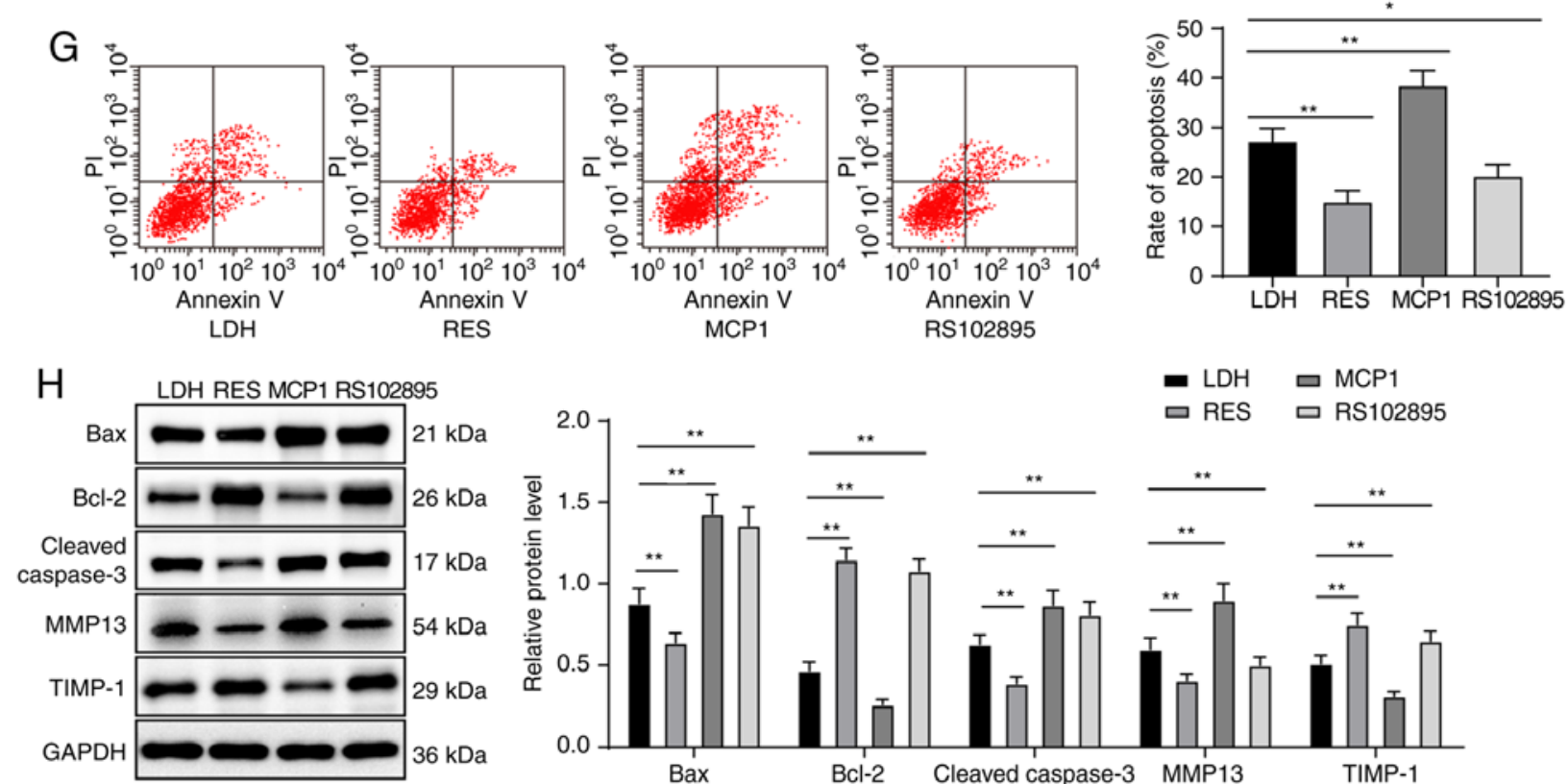

$$
\square \text { RES } \square \text { RS102895 }
$$

Figure 2. Overexpression of SIRT1 and downregulation of the MCP1/CCR2 axis increases NPMSC cartilage differentiation and inhibits NPMSC apoptosis. (A-D) According to RT-qPCR and western blot analyses, the RES group displayed increased mRNA and protein expression of SIRT1, the MCP1 group exhibited increased mRNA and protein expression of MCP1 and CCR2, and the RS102895 group presented decreased mRNA and protein expression of CCR2 compared with the LDH group. (E and F) Compared with the LDH group, the RES and RS102895 groups displayed increased mRNA and protein expression of aggrecan, collagen II and Sox-9, and the MCP1 group exhibited decreased mRNA and protein expression of aggrecan, collagen II and Sox-9, as shown by the results of RT-qPCR and western blot analyses. (G) According to the flow cytometry results, apoptosis was decreased in the RES and RS102895 groups but increased in the MCP1 group compared with the LDH group. (H) Western blot analysis showed decreased expression levels of Bax, cleaved caspase-3 and TIMP-1 and increased levels of Bcl-2 and MMP13 in the RES and RS102895 groups compared with the LDH group; the opposite results were observed in the MCP1 group. Data in panels A, C, D and E were analyzed using t tests, data in panels A, B, E, F and H were analyzed using two-way ANOVA, and data in panel G were analyzed using one-way ANOVA. Tukey's multiple comparisons test was applied as the post hoc test. $\mathrm{n}=3$. ${ }^{*} \mathrm{P}<0.05$ and ${ }^{* *} \mathrm{P}<0.01 ;{ }^{\# \#} \mathrm{P}<0.01$. SIRT, Sirtuin; MCP, monocyte chemoattractant protein; CCR, chemokine receptor; NPMSC, nucleus pulposus mesenchymal stem cell; RT-qPCR, reverse transcription-quantitative polymerase chain reaction; LDH, lumbar disc herniation; RES, resveratrol; Sox, Sry related HMG box; Bax, Bcl-2-associated X; TIMP1, tissue inhibitor of metalloproteinase 1. 

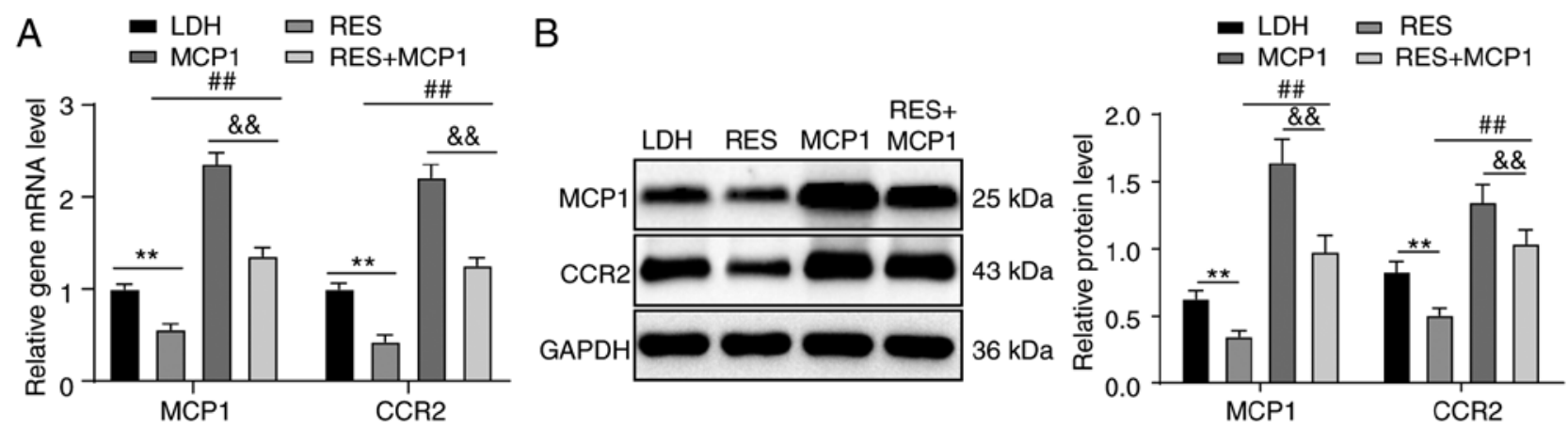

Figure 3. Overexpression of SIRT1 downregulates the MCP1/CCR2 axis. According to (A) RT-qPCR and (B) western blot analyses, increased mRNA and protein expression of MCP1 and CCR2 were observed in the RES group, and higher mRNA and protein expression of MCP1 and CCR2 were observed in the RES + MCP1 group compared with in the RES group, but the levels were lower than those of the MCP1 group. Two-way ANOVA, followed by Tukey's multiple comparisons test as the post hoc test, were used to determine statistical significance. $n=3 .{ }^{* * *} \mathrm{P}<0.01$; ${ }^{\# \#} \mathrm{P}<0.01$; ${ }^{\text {\&\&}} \mathrm{P}<0.01$. SIRT, Sirtuin; MCP, monocyte chemoattractant protein; CCR, chemokine receptor; RT-qPCR, reverse transcription-quantitative polymerase chain reaction; RES, resveratrol; LDH, lumbar disc herniation.

apoptosis, decreased expression of Bcl-2 and TIMP-1, and increased expression of Bax, cleaved caspase- 3 and MMP13 (all P<0.05; Fig. 4A-D).

Transplantation of rat NPMSCs overexpressing SIRT1 relieves $I D D$ in rats by downregulating the MCPI/CCR2 axis. In the IDD group, mRNA and protein expression levels of MCP1 and CCR2 increased, and expression of SIRT1 mRNA and protein decreased. In contrast, in the LV NC and LV-SIRT1 groups, mRNA and protein expression levels of MCP1 and CCR2 decreased, and expression of SIRT1 mRNA and protein increased compared with IDD rats (all $\mathrm{P}<0.05$; Fig. 5A and B). $\mathrm{H} \& \mathrm{E}$ staining revealed a normal intervertebral space and orderly arrangement of the annulus fibrosus in normal rats of the control group. Meanwhile, in IDD rats, intervertebral spaces were narrowed, the annulus fibrosus was disordered and the NP matrix was decreased. When rat NPMSCs or rat NPMSCs overexpressing SIRT1 were transplanted, the annulus fibrosus displayed an orderly arrangement and the intervertebral structure had recovered notably (Fig. 5C). Lower mRNA and protein expression levels of aggrecan, collagen II and Sox-9 were observed in IDD rats compared with in rats of the control group, and those changes were reversed by the transplantation of NPMSCs or NPMSCs overexpressing SIRT1 (all $\mathrm{P}<0.01$; Fig. 5D and E). TUNEL staining revealed increased apoptosis in IDD rats compared with rats in the control group, but apoptosis was reduced after rat NPMSC transplantation and decreased even further when rat NPMSCs overexpressing SIRT1 were transplanted (all $\mathrm{P}<0.01$; Fig. 5F). Compared with the control group, the IDD group displayed increased protein expression levels of Bax and cleaved caspase-3, but decreased protein expression of $\mathrm{Bcl}-2$. These changes were reversed by the transplantation of rat NPMSCs or rat NPMSCs overexpressing SIRT1 (all P<0.05; Fig. 5G).

\section{Discussion}

As one of the most common human spinal conditions, IDD is primarily characterized by the degeneration of NP cells (21). NPMSC proliferation, stemness preservation and colony formation are decreased, whereas apoptosis is increased in individuals with IDD (22). Additionally, SIRT1 exerts a protective effect on IDD, and its expression is downregulated in the degenerating disc (23). Although multiple studies on IDD and SIRT1 or IDD and NPMSCs have been conducted, only a few have focused on the interaction among these three factors, and even fewer have analyzed possible signaling pathways. Therefore, the present study aimed to identify some novel therapies for IDD based on SIRT1. These data indicated that SIRT1 increased NPMSC differentiation into cartilage and reduced apoptosis by downregulating the MCP1/CCR2 axis.

First, an MTT assay and RT-qPCR found that compared with the normal NPMSCs, NPMSCs from LDH patients exhibited expression of CD73 and CD90, but not CD34 and CD45, decreased expression of Oct4 and Nanog, and decreased NPMSC proliferation rate and SIRT1 expression. As reported by Liu et al (24), IDD stem cells exhibit high CD73 and CD90 expression, low CD34 and CD45 expression, and downregulated expression of genes related to stem cells, including Oct 4 and Nanog, which is consistent with the present findings. Nevertheless, NPMSC proliferation and viability decrease in response to hypoxia-triggered IDD (25). In a previous study, SIRT1 expression decreased in IDD cells (26). Additionally, MCP1 and CCR2 expression increased in subjects with LDH compared with healthy subjects in the present study. It has been demonstrated that MCP1 is activated in NP cells, and it can exacerbate vertebral erosion (27). Additionally, high expression of MCP1 indicates an increase in spinal pressure pain sensitivity and overall pain ratings (28). CCR2 is mainly expressed in neurons and macrophages, and it is responsible for cumulative pain hypersensitivity resulting from autologous NP implantation in patients with LDH (29). In the present study, SIRT1 overexpression increased differentiation of NPMSCs into cartilage, but inhibited cell apoptosis. NPMSCs alleviate IDD by differentiating into cells that closely resemble NP cells and improving the function of disc cells (25). Meanwhile, the degeneration of cartilage end plates induces IDD (26). When SIRT1 was upregulated, the expression of aggrecan, collagen II and Sox-9 also increased in the present study. This is consistent with a previous finding that 

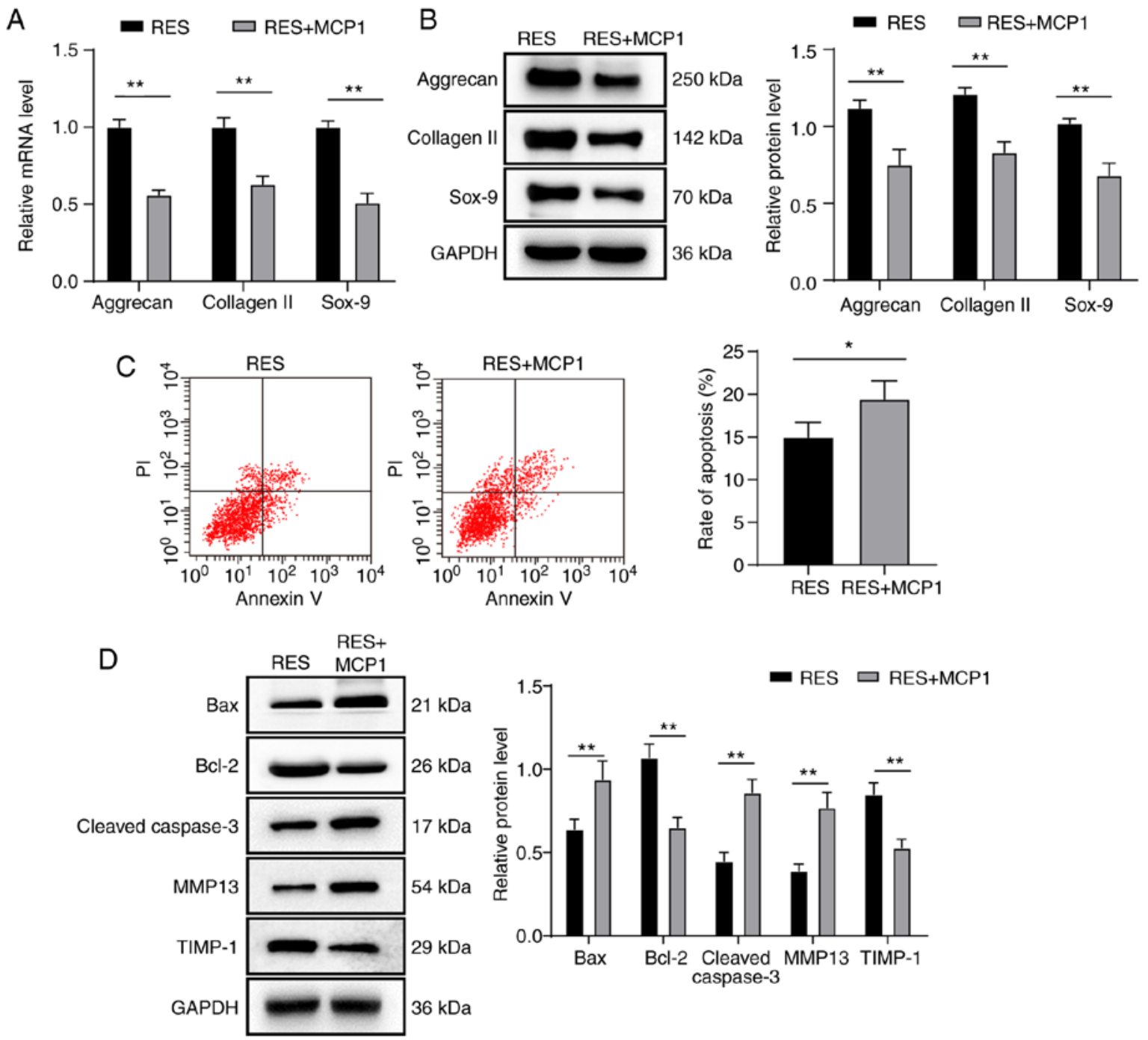

Figure 4. MCP1 reverses the progression of NPMSC cartilage differentiation and the inhibition of NPMSC apoptosis induced by SIRT1 overexpression. (A-D) Compared with the RES group, the RES + MCP1 group displayed decreased mRNA and protein expression levels of aggrecan, collagen II and Sox-9, lower levels of cell apoptosis, decreased protein expression of Bcl-2 and TIMP-1, and increased protein expression of Bax, cleaved caspase-3 and MMP13, based on the results of (A) RT-qPCR, (B and D) western blotting and (C) flow cytometry. Data in panel C were analyzed using a t test; data in panels A, B and D were analyzed using two-way ANOVA. Tukey's multiple comparisons test was applied as the post hoc test. $\mathrm{n}=3$. ${ }^{*} \mathrm{P}<0.05$ and ${ }^{* *} \mathrm{P}<0.01$. MCP, monocyte chemoattractant protein; NPMSC, nucleus pulposus mesenchymal stem cell; SIRT, Sirtuin; RES, resveratrol; Sox, Sry related HMG box; Bcl-2, B-cell lymphoma-2; TIMP1, tissue inhibitor of metalloproteinase 1; Bax, Bcl-2-associated X; MMP, matrix metalloproteinase; RT-qPCR, reverse transcription-quantitative polymerase chain reaction.

activated SIRT1 can reverse the degeneration of aggrecan and collagen II (21). Moreover, the apoptosis rate of NPMSCs decreased after SIRT1 overexpression, which was accompanied by decreased expression of Bax, cleaved caspase- 3 and MMP13, and increased expression of TIMP-1 and Bcl-2. According to the findings of He et al (30), overexpression of SIRT1 reduces chondrocyte apoptosis and ECM degeneration in subjects with osteoarthritis (OA) by increasing Bcl-2 expression and inhibiting Bax expression. Furthermore, in spinal cord injuries, when SIRT1 is upregulated, cleaved caspase-3 expression was reduced, suggesting a negative association between these two proteins (31). Fujita et al (32) revealed that overexpression of SIRT1 in chondrocytes suppresses OA gene expression, such as MMP-13.

In addition, the present study revealed that MCP1 reversed the progression of NPMSC differentiation into cartilage and inhibited SIRT1-induced cell apoptosis. It was previously reported that in NPMSCs, MCP1 expression is notably reduced (33). SIRT1 overexpression downregulates MCP1, whereas the loss of SIRT1 increases MCP1 expression, indicating a negative association between these two proteins (34). The present study demonstrated that after MCP1 treatment TIMP-1 expression decreased. In a recent study, MCP1 expression decreased, whereas TIMP-1 expression increased in cells treated with canagliflozin (35). Moreover, in the present study the transplantation of SIRT1-overexpressing NPMSCs relieved IDD in rats by downregulating the MCP1/CCR 2 axis. The transplantation of MSCs into patients with IDD could alleviate IDD by inhibiting NP cell apoptosis (36). According to a previous study, SIRT1 maintains MSC stemness, thus mitigating age-related skeletal disorders, such as osteoporosis (37). Overall, SIRT1 represents a potential target for the treatment of IDD.

In summary, the present study supported the hypothesis that SIRT1 induces cartilage differentiation and inhibits the 
A

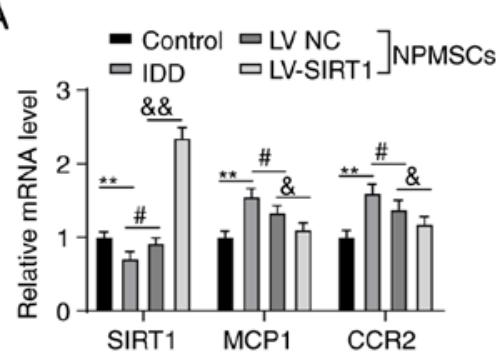

B

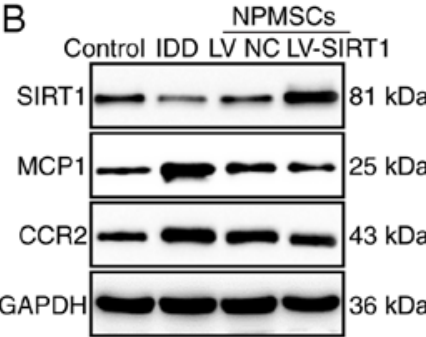

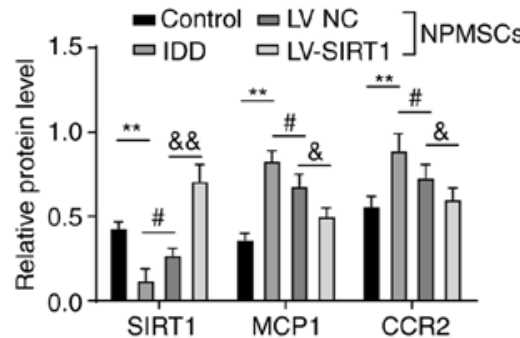

C
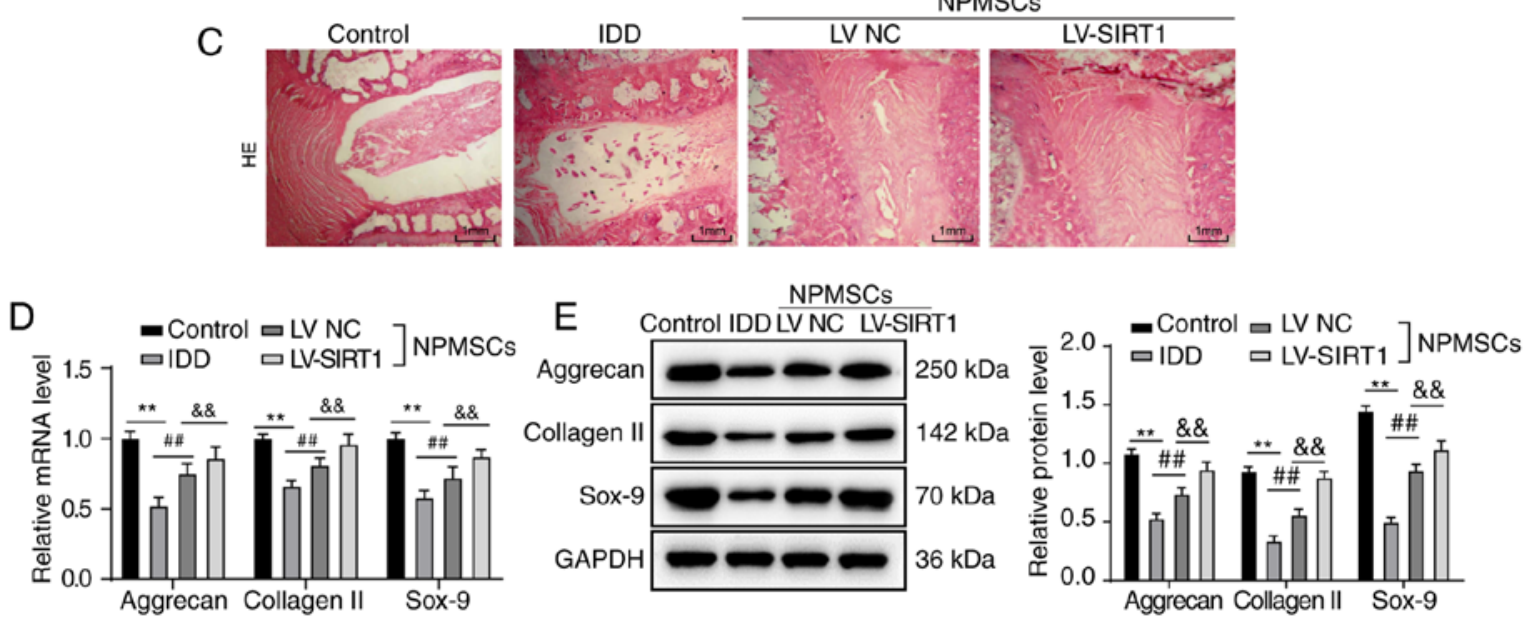

$F$ TUNEL
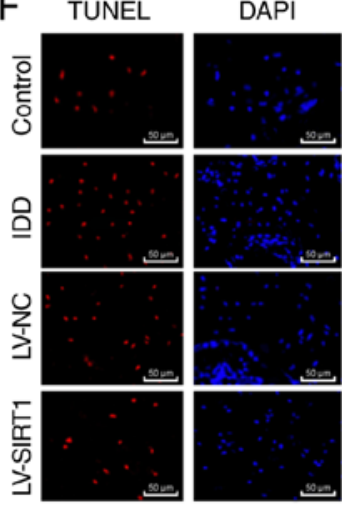

Merge
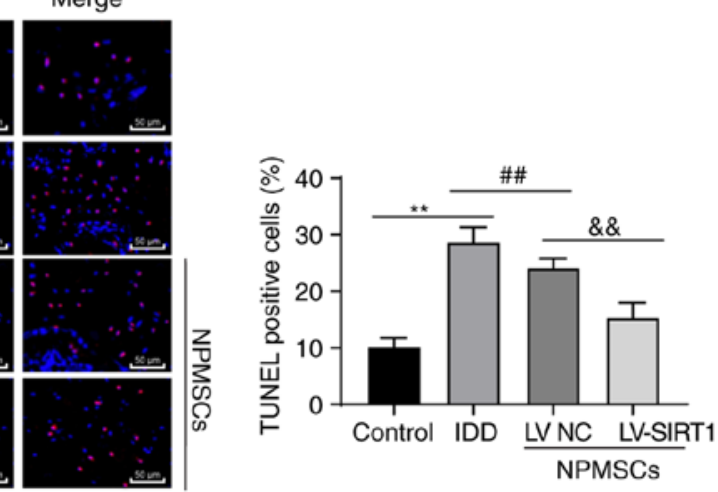

G

NPMSC
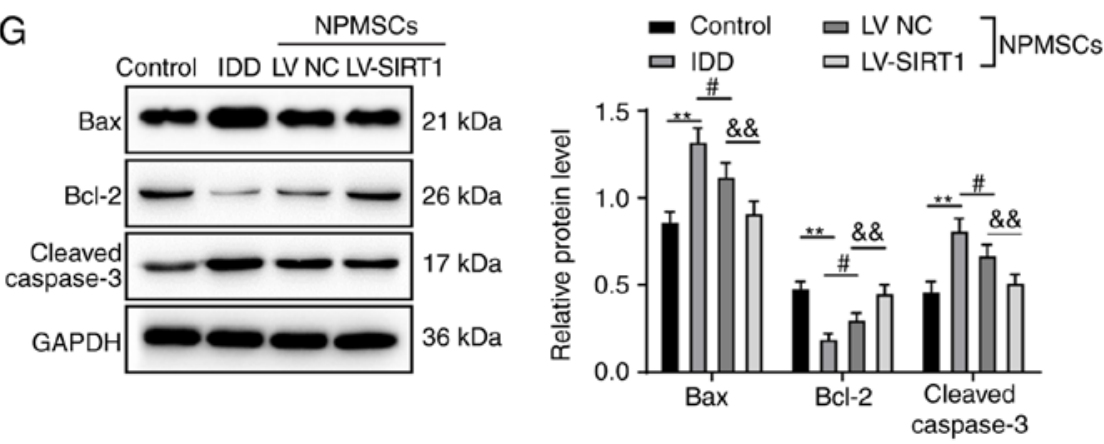

Figure 5. Transplantation of rat NPMSCs overexpressing SIRT1 relieves IDD in rats by downregulating the MCP1/CCR2 axis. (A) RT-qPCR and (B) western blot analyses showed increased mRNA and protein expression of MCP1 and CCR2, and reduced mRNA and protein expression of SIRT1 in the IDD group compared with the control group. In contrast, the mRNA and protein expression of MCP1 and CCR2 decreased and mRNA and protein expression of SIRT1 increased in the IDD rats after transplantation of the NPMSCs or SIRT1-overexpressing NPMSCs, $n=4$. (C) H\&E staining revealed an amelioration of the disordered intervertebral structure after the transplantation of NPMSCs or SIRT1-overexpressing NPMSCs, n=6. Based on the (D) RT-qPCR and (E) western blot analyses, lower mRNA and protein expression levels of aggrecan, collagen II and Sox-9 were observed in IDD rats compared with in rats of the control group, $n=4$. (F) TUNEL staining revealed increased cell apoptosis in IDD rats compared with rats in the control group, which was reduced by NPMSC transplantation and even further decreased after the transplantation of SIRT1-overexpressing NPMSCs, $\mathrm{n}=6$. (G) Western blotting showed higher protein expression of Bax and cleaved caspase- 3 and lower expression of Bcl-2 in the IDD group compared with in the control group, and these changes were reversed by the transplantation of NPMSCs or SIRT1-overexpressing NPMSCs, $n=4$. Data in panel F were analyzed using one-way ANOVA; data in panels A, B, C, D, $\mathrm{E}$ and $\mathrm{G}$ were analyzed using two-way ANOVA. Tukey's multiple comparisons test was applied as the post hoc test. ${ }^{* *} \mathrm{P}<0.01 ;{ }^{\#} \mathrm{P}<0.05$ and ${ }^{\# \#} \mathrm{P}<0.01 ;{ }^{\&} \mathrm{P}<0.05$ and ${ }^{\&} \mathrm{P}<0.01$. NPMSC, nucleus pulposus mesenchymal stem cell; IDD, intervertebral disc degeneration; SIRT, Sirtuin; MCP, monocyte chemoattractant protein; CCR, chemokine receptor; RT-qPCR, reverse transcription-quantitative polymerase chain reaction; HE, hematoxylin-eosin; Sox, Sry related HMG box; TUNEL, tdT-mediated dUTP nick-end labeling; Bcl-2, B-cell lymphoma-2; Bax, Bcl-2-associated X. 
apoptosis of NPMSCs in individuals with IDD by inhibiting the MCP1/CCR2 axis. These results reveal a novel theoretical approach for IDD treatment. However, this study simply describes preclinical research. Although these findings provide therapeutic implications for IDD treatment, the experimental results and effective application in clinical practice require further validation. Future studies will further explore the underlying mechanisms of other targets of SIRT1 by focusing on the identification of reliable therapeutic targets for IDD and the application of the results of the present study in clinical settings for IDD treatment.

\section{Acknowledgements}

Not applicable.

\section{Funding}

This study was supported by a grant from the National Natural Science Foundation of China (grant no. 81772399).

\section{Availability of data and materials}

All the data generated or analyzed during the present study are included in this published article.

\section{Authors' contributions}

DR is the guarantor of the integrity of the entire study and contributed to the conception and design of this study. XO contributed to the definition of intellectual content, clinical studies, experimental studies, data analysis and manuscript preparation and editing. JY and XO contributed to the literature search. $\mathrm{XO}$ and $\mathrm{CW}$ contributed to data acquisition. $\mathrm{XB}$, $\mathrm{CW}$ and JY were responsible for the statistical analyses. DR contributed to the manuscript review. All authors read and approved the final manuscript.

\section{Ethics approval and consent to participate}

This study was approved and supervised by the ethics committee of The Sixth Medical Centre of PLA General Hospital. All subjects provided signed informed consent. The protocol was also approved by the Institutional Animal Care and Use Committee of The Sixth Medical Centre of PLA General Hospital. Significant efforts were made to minimize both the number of animals used and their respective suffering.

\section{Patient consent for publication}

Not applicable.

\section{Competing interests}

The authors declare that they have no competing interests.

\section{References}

1. Loibl M, Wuertz-Kozak K, Vadala G, Lang S, Fairbank J and Urban JP: Controversies in regenerative medicine: Should intervertebral disc degeneration be treated with mesenchymal stem cells? JOR Spine 2: e1043, 2019.
2. Kaiser J, Allaire B, Fein PM, Lu D, Jarraya M, Guermazi A, Demissie S, Samelson EJ, Bouxsein ML and Morgan EF: Correspondence between bone mineral density and intervertebral disc degeneration across age and sex. Arch Osteoporos 13: 123, 2018.

3. Li XC, Wang MS, Liu W, Zhong CF, Deng GB, Luo SJ and Huang CM: Co-culturing nucleus pulposus mesenchymal stem cells with notochordal cell-rich nucleus pulposus explants attenuates tumor necrosis factor- $\alpha$-induced senescence. Stem Cell Res Ther 9: 171, 2018.

4. Li H, Wang J, Li F, Chen G and Chen Q: The influence of hyperosmolarity in the intervertebral disc on the proliferation and chondrogenic differentiation of nucleus pulposus-derived mesenchymal stem cells. Cells Tissues Organs 205: 178-188, 2018.

5. Chen S, Zhao L, Deng X, Shi D, Wu F, Liang H, Huang D and Shao Z: Mesenchymal stem cells protect nucleus pulposus cells from compression-induced apoptosis by inhibiting the mitochondrial pathway. Stem Cells Int 2017: 9843120, 2017.

6. Mohanty S and Dahia CL: Defects in intervertebral disc and spine during development, degeneration, and pain: New research directions for disc regeneration and therapy. Wiley Interdiscip Rev Dev Biol 8: e343, 2019.

7. Jezierska-Wozniak K, Barczewska M, Habich A, Wojtacha P, Badowska W, Maksymowicz W and Wojtkiewicz J: The feasibility of the CD271+ and CD271-mesenchymal stromal cell enrichment toward nucleus pulposus-like cells. Folia Histochem Cytobiol 55: 114-123, 2017.

8. Lee SH, Lee JH, Lee HY and Min KJ: Sirtuin signaling in cellular senescence and aging. BMB Rep 52: 24-34, 2019.

9. Bradley EW, Carpio LR, van Wijnen AJ, McGee-Lawrence ME and Westendorf JJ: Histone deacetylases in bone development and skeletal disorders. Physiol Rev 95: 1359-1381, 2015.

10. Almeida M and Porter RM: Sirtuins and FoxOs in osteoporosis and osteoarthritis. Bone 121: 284-292, 2019.

11. Sun W, Qiao W, Zhou B, Hu Z, Yan Q, Wu J, Wang R, Zhang Q and Miao D: Overexpression of Sirtl in mesenchymal stem cells protects against bone loss in mice by FOXO3a deacetylation and oxidative stress inhibition. Metabolism 88: 61-71, 2018.

12. Wang Y, Ni H, Li H, Deng H, Xu LS, Xu S, Zhen Y, Shen H, Pan H and Yao M: Nuclear factor kappa B regulated monocyte chemoattractant protein-1/chemokine CC motif receptor-2 expressing in spinal cord contributes to the maintenance of cancer-induced bone pain in rats. Mol Pain 14: 1744806918788681, 2018.

13. Faienza MF, D'Amato G, Chiarito M, Colaianni G, Colucci S, Grano M, Corbo F and Brunetti G: Mechanisms involved in childhood obesity-related bone fragility. Front Endocrinol (Lausanne) 10: 269, 2019.

14. Xie Z, Wang P, Li J, Li Y, Wang S, Wu X, Sun S, Cen S, Su H, Deng W, et al: MCP1 triggers monocyte dysfunctions during abnormal osteogenic differentiation of mesenchymal stem cells in ankylosing spondylitis. J Mol Med (Berl) 95: 143-154, 2017.

15. Arkestal K, Mints M, Enocson A, Linton L, Marits P, Glise H, Andersson $J$ and Winqvist O: CCR2 upregulated on peripheral $\mathrm{T}$ cells in osteoarthritis but not in bone marrow. Scand J Immunol 88: e12722, 2018.

16. Wang L, Kang S, Zou D, Zhan L, Li Z, Zhu W and Su H: Bone fracture pre-ischemic stroke exacerbates ischemic cerebral injury in mice. PLoS One 11: e0153835, 2016.

17. Hui X, Zhang M, Gu P, Li K, Gao Y, Wu D, Wang Y and Xu A: Adipocyte SIRT1 controls systemic insulin sensitivity by modulating macrophages in adipose tissue. EMBO Rep 18: 645-657, 2017.

18. Yang X, Wei J, He Y, Jing T, Li Y, Xiao Y, Wang B, Wang W, Zhang J and Lin R: SIRT1 inhibition promotes atherosclerosis through impaired autophagy. Oncotarget 8: 51447-51461, 2017.

19. Han B, Zhu K, Li FC, Xiao YX, Feng J, Shi ZL, Lin M, Wang J and Chen QX: A simple disc degeneration model induced by percutaneous needle puncture in the rat tail. Spine (Phila Pa 1976) 33: 1925-1934, 2008

20. Zatroch KK, Knight CG, Reimer JN and Pang DS: Refinement of intraperitoneal injection of sodium pentobarbital for euthanasia in laboratory rats (Rattus norvegicus). BMC Vet Res 13: 60, 2017.

21. Song Y, Wang Z, Liu L, Zhang S, Zhang H and Qian Y: 1,4-Dihydropyridine (DHP) suppresses against oxidative stress in nucleus pulposus via activating sirtuin-1. Biomed Pharmacother 121: 109592, 2020.

22. Liu Y, Li Y, Huang ZN, Wang ZY, Nan LP, Wang F, Zhou SF, Wang JC, Feng XM and Zhang L: The effect of intervertebral disc degenerative change on biological characteristics of nucleus pulposus mesenchymal stem cell: An in vitro study in rats. Connect Tissue Res 60: 376-388, 2019. 
23. Guo J, Shao M, Lu F, Jiang J and Xia X: Role of Sirt1 plays in nucleus pulposus cells and intervertebral disc degeneration. Spine (Phila Pa 1976) 42: E757-E766, 2017.

24. Liu J, Tao H, Wang H, Dong F, Zhang R, Li J, Ge P, Song P, Zhang $\mathrm{H}$, Xu P, et al: Biological behavior of human nucleus pulposus mesenchymal stem cells in response to changes in the acidic environment during intervertebral disc degeneration. Stem Cells Dev 26: 901-911, 2017.

25. Liang H, Chen S, Huang D, Deng X, Ma K and Shao Z: Effect of compression loading on human nucleus pulposus-derived mesenchymal stem cells. Stem Cells Int 2018: 1481243, 2018.

26. Zhou N, Lin X, Dong W, Huang W, Jiang W, Lin L, Qiu Q Zhang X, Shen J, Song Z, et al: SIRT1 alleviates senescence of degenerative human intervertebral disc cartilage endo-plate cells via the p53/p21 pathway. Sci Rep 6: 22628, 2016

27. Zhu Z, Huang P, Chong Y, George SK, Wen B, Han N, Liu Z, Kang L and Lin N: Nucleus pulposus cells derived IGF-1 and MCP-1 enhance osteoclastogenesis and vertebrae disruption in lumbar disc herniation. Int J Clin Exp Pathol 7: 8520-8531, 2014.

28. Palada V, Ahmed AS, Finn A, Berg S, Svensson CI and Kosek E: Characterization of neuroinflammation and periphery-to-CNS inflammatory cross-talk in patients with disc herniation and degenerative disc disease. Brain Behav Immun 75: 60-71, 2019

29. Zhu X, Cao S, Zhu MD, Liu JQ, Chen JJ and Gao YJ: Contribution of chemokine CCL2/CCR2 signaling in the dorsal root ganglion and spinal cord to the maintenance of neuropathic pain in a rat model of lumbar disc herniation. J Pain 15: 516-526, 2014.

30. He DS, Hu XJ, Yan YQ and Liu H: Underlying mechanism of Sirt1 on apoptosis and extracellular matrix degradation of osteoarthritis chondrocytes. Mol Med Rep 16: 845-850, 2017.

31. Zhao H, Chen S, Gao K, Zhou Z, Wang C, Shen Z, Guo Y, Li Z, Wan Z, Liu C and Mei X: Resveratrol protects against spinal cord injury by activating autophagy and inhibiting apoptosis mediated by the SIRT1/AMPK signaling pathway. Neuroscience 348 : 241-251, 2017.
32. Fujita N, Matsushita T, Ishida K, Kubo S, Matsumoto T, Takayama K, Kurosaka M and Kuroda R: Potential involvement of SIRT1 in the pathogenesis of osteoarthritis through the modulation of chondrocyte gene expressions. J Orthop Res 29: 511-515, 2011

33. Suvakov S, Cubro H, White WM, Tobah YSB, Weissgerber TL, Jordan KL, Zhu XY, Woollard JR, Chebib FT, Milic NM, et al: Targeting senescence improves angiogenic potential of adipose-derived mesenchymal stem cells in patients with preeclampsia. Biol Sex Differ 10: 49, 2019.

34. Li Y, Wang P, Yang X, Wang W, Zhang J, He Y, Zhang W, Jing T, Wang B and Lin R: SIRT1 inhibits inflammatory response partly through regulation of NLRP3 inflammasome in vascular endothelial cells. Mol Immunol 77: 148-156, 2016.

35. Nasiri-Ansari N, Dimitriadis GK, Agrogiannis G, Perrea D, Kostakis ID, Kaltsas G, Papavassiliou AG, Randeva HS and Kassi E: Canagliflozin attenuates the progression of atherosclerosis and inflammation process in APOE knockout mice. Cardiovasc Diabetol 17: 106, 2018.

36. Cheng X, Zhang G, Zhang L, Hu Y, Zhang K, Sun X, Zhao C, Li H, Li YM and Zhao J: Mesenchymal stem cells deliver exogenous miR-21 via exosomes to inhibit nucleus pulposus cell apoptosis and reduce intervertebral disc degeneration. J Cell Mol Med 22: 261-276, 2018.

37. Lin CH, Li NT, Cheng HS and Yen ML: Oxidative stress induces imbalance of adipogenic/osteoblastic lineage commitment in mesenchymal stem cells through decreasing SIRT1 functions. J Cell Mol Med 22: 786-796, 2018.

This work is licensed under a Creative Commons Attribution-NonCommercial-NoDerivatives 4.0 International (CC BY-NC-ND 4.0) License. 